\title{
Affiliation and aggression in rats
}

\author{
GEORGE T. TAYLOR \\ University of Missouri - St. Louis, 8001 Natural Bridge Road, St. Louis, Missouri 63121
}

\begin{abstract}
The relationship between affiliation and aggression was examined in two experiments. In the first study, each of 12 male albino rats was allowed to choose in a T-maze between two alternatives. One alternative housed a more aggressive target male and the other housed a less aggressive target male. The subjects preferred the less aggressive target animal. A second investigation allowed each of 36 male albino rats to choose between a target animal and an empty compartment. The results were that all the subjects preferred to affiliate with the target animal. However, as the level of aggressiveness by the target animal increased, the level of gregariousness decreased. The data suggest that an important determinant of affiliation is the behavior, and specifically the aggressiveness, of the target animal.
\end{abstract}

Two behaviors which occur with high frequency among same-sex conspecifics are affiliation and aggression. Male rats actively seek another male rat, and the animals remain in close proximity for long periods of time (Angermeier, 1960; Sloan \& Latane, 1974). Usually the social interactions are amicable or friendly, characterized by nuzzling, sniffing, and huddling (Ewer, 1968). At times, however, the peaceful social behavior erupts into aggressive behaviors (Cairns \& Scholz, 1973).

The previous research has, for the most part, stressed either the aggressive aspects (Scott, 1966) or the affiliation aspects (Latane \& Hothersall, 1972) of the social encounter. Seldom has the relationship between the two behaviors been thoroughly investigated. A notable exception was a study reported by Lagerspetz (1964) using mice. She had found that, following a defeat, a mouse was less likely to seek its conqueror. These data point to the conclusion that the behaviors, and specifically aggressive behaviors, of the "other" animal will importantly influence gregariousness.

Two experiments were designed to explore more fully the relationship between aggression and affiliation. In both experiments, rats were allowed a choice in a T-maze. For either choice, there was a same-sex conspecific in the goal area. The probability of affiliation was related to the aggressiveness of the waiting, target animal.

\section{EXPERIMENT I}

In the initial experiment, medium-aggressive experimental animals were given a choice between two social alternatives. A highly aggressive target rat was one alternative and a less aggressive target rat was the other. The presumption was that the experimental subject could socially interact with both, yet the number and

A portion of this paper was completed while the author was at the State University of New York, College at Potsdam, and was supported in part by a grant from the Research Foundation of the State University of New York.

Reprints may be obtained from G. T. Taylor, Department of Psychology, University of Missouri - St. Louis, 8001 Natural Bridge Road, St. Louis, Missouri 63121 . intensity of the aggressions by the target animal against the subject would differ.

\section{Method}

Subjects. liorty Holtzman male albino rats obtained from a commercial supplier were used, although only 24 were employed as subjects in the actual experument. The experimentally naive subjects were approvinately 100 days old at the beginning of experimentation. The animals were individually housed.

During testing for relative aggressiveness, the animals were water deprived. Each received 5-min free access to water immediately following the daily experimental session. At all other times, food and water were freely available.

Apparatus. A wooden T-maze (see Taylor, 1974) with $1.29-\mathrm{m}$ runway and $.57-\mathrm{m}$ arms, one of which was painted white and the other black, was used. The startbox measured $24 \times 11.6 \times 16.8 \mathrm{~cm}$ and the goalbox was $25 \times 11.6 \times 16.8 \mathrm{~cm}$. The floor of the apparatus was hardware cloth and the top was Plexiglas. Five doors, each $11.6 \times 16.8 \mathrm{~cm}$, were raised and lowered manually. The doors were located directly after the startbox, at the beginning of each of the arms, and immediately preceding each goal area.

A water-dominance apparatus was used to establish the relative social position of the males. The apparatus was a rectangular unit constructed of Masonite and containing two adjacent startboxes, each $18 \times 18 \times 30.5 \mathrm{~cm}$, and a larger connecting arena, $28 \times 36 \times 30.5 \mathrm{~cm}$. A vertically moveable startdoor was located between the startboxes and the arena. At the end of the arena, opposite to the entrance from the startbox, was a small water cup. The size of the cup was such that one animal drinking precluded the other animal from drinking.

\section{Procedure}

Test of aggressiveness. The group of 40 males was initially tested for relative aggressiveness, i.e., dominance-submission, using a procedure employed in the earlier research (Taylor, 1975; Taylor \& Moore, 1975). The thirsty animals were individually placed into a water-dominance box in which water was available in a small cup large enough for only one animal's head. Following five daily 10 -min individual training sessions in which the animals drank from the cup, the males were randomly paired until the six most aggressive (dominant), the six least aggressive (submissive), and the 12 intermediate-(midrange)aggressive animals were determined. The midrange animals were simply the rats in the middle of the social hierarchy. The remaining rats were discarded from the experiment.

The concept of dominance has been justifiably criticized recently as being overrated (Rowell, 1974) and misused (Syme, Pollard, Syme, \& Reid, 1974). However, in the present studies the relative dominance/submission was defined purely in terms 
of aggression. Deprivation-nduced competition for the limited quantity of water has proven to be a successful procedure for measuring aggressiveness in the albino rat (Taylor, 1975). Aggressive behaviors were observed and recorded during competition for the water and for several minutes after the water had been consumed. These observations formed the basis for the sociai hierarchy.

Aggression categories. The aggressive behaviors recorded were those described in detail by Grant (1963) and Grant and Mackintosh (1963). The behaviors included were threats, pushing, crawling over-and-under, aggressive grooms (dominant animal uses its teeth and paws to vigorously pull the fur at the shoulder region of the submissive rat), and mounts (the domnant animal mounts the submissive male and palpitates with pelvic thrusts). Also observed were aggressive postures (the dominant rat crentates at right angles to and over the submissive's body) and, more infrequently, at tacks with bitıng. Though not all investigators agree on the precise identification of aggression, the social behaviors described are commonly cited as instances of hostile behaviors (Barnett, 1963; Zook \& Adams, 1975). The incidences of each form of aggression were recorded and the instances of each type summed to produce a daily aggression score.

Experimental training. The mdrange experimental subjects were given four spaced trials each day to either of two goal areas. Always at one goalbox, white for halt the males and black for the other males. was one of the highly aggressive, dominant target rats. The opposite goal locus contained one of the less aggressive, submissive target animals. The group of dominant targets and submissive targets was randomly sequenced so that the experimental subject never experienced the same target male twice on the same day. This procedure maximized aggressiveness A pair of animals establishes a social order with increased amounts of exposure, and aggressions are subsequently reduced (Barnett, 1963).

The daily training sessions consisted of first two free-choice trials in which each of the midrange experimental animals could choose one of the two target animals. The third and fourth trials were forced-choice trials. That is, the subject was forced to the side opposite that chosen on the free trials. The free-forced sequence insured equal experiences each day to the two alternatives. The procedure allowed for oreference testing, yet also allowed the number of opportunities for aggression with the dominant target and the submissive target to be held constant (at two each) daily.

Before each trial, a dominant target was placed in the appropriate goal area and the submissive target was placed in the other goalbox. A trial was initiated by placing a midrange animal into the startbox and raising the startdoor. On a free-choice trial, both arm doors were open and the subject could view, and had access to, both arms. If the trial was a forced one, the appropriate arm door remained closed and the animal was forced to run into the opened arm.

To keep the animals from interacting until after the experimental subject was in the arm, the goal door remained closed until after the animal had entered the arm of the maze. The arm door was then lowered to capture the animal in that alternative. Quickly the goal door was raised and the animals allowed to interact. The experimental animals remained in the goal area for $1 \mathrm{~min}$, where they were observed and the aggressive behaviors were recorded.

The midrange rat was then removed to a retaining cage for approximately $3 \mathrm{~min}$ and the next trial. Note that the males could not see each other until after the experimental subject entered the arm and the arm door was closed. Thus, the midrange animals had to learn to discriminate the two choices, presumably, on the basis of the different brightnesses of the arms of the T-maze. Finally, the animals were run for 24 consec- utive days and 96 tulals, 1.e.. 48 trials to a dominant target and 48 trials to a submissive target.

\section{Results}

The two principal behaviors systematically recorded in the experiment were the animals' prefesences and the incidences of aggiession. These data were of importance to examine the relationship between aggression and affiliation. The results offer strong support for the notion that an animal will choose an alternative in which it can obtain social contact and yet minimize being aggressed against.

Preference behaviors. The midrange rats' preferences were measured by recording the alternative chosen on the two daily free-chorce trials. Those data were combined and a mean percentage of choices to the submissive target animal was calculated (No. of choices to submissive animal/No. of free-choice trials $x$ 100) each day. The results appear in Figure 1. The findings suggest an increasingly higher preference for the submissive animal over the training sessions, terminating at near $100 \%$. Statistical analyses indicated that the midrange anumals significantly preferred the side of the maze containung the submissive target animal. $\chi^{2}(1)=215.12, p<.001 .1$

Aggressive behaviors The two daly free-choce trials were always followed by two forced-choce trals to the opposite arm from that chosen on the free trals. As a result, the mudrange anmmal mteracted w'th the domnnant target rat and with the submissive target rat twice

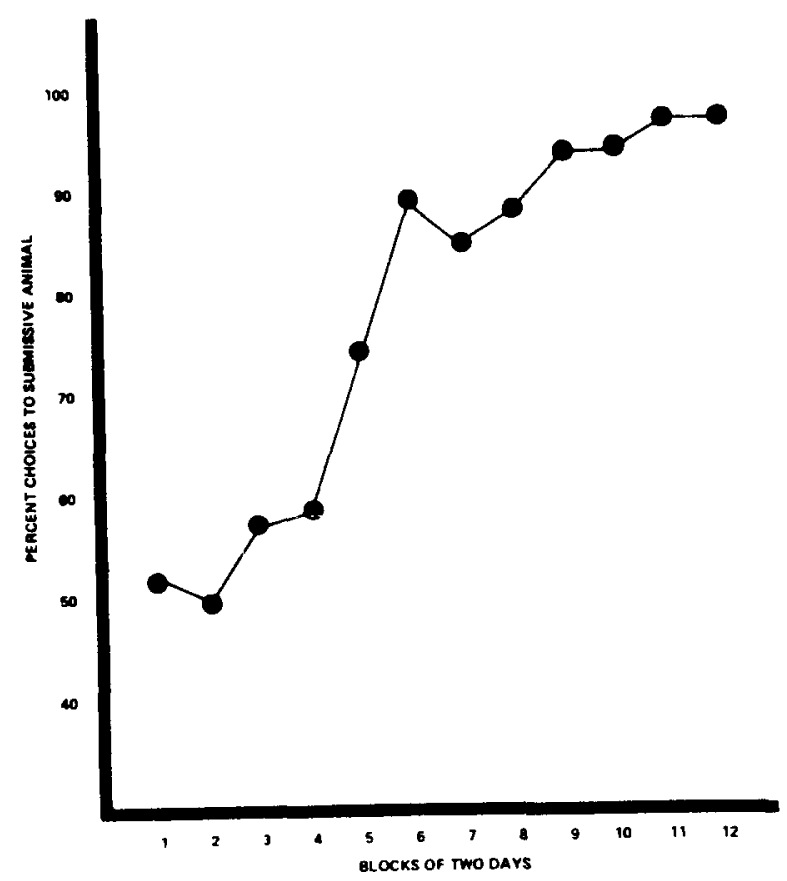

Figure 1. The percentage of choices by the midrange aggres sive experimental subjects to the submissive target rat. 
each day. During these interactions, the number of aggressions initiated by each animal was recorded. The mean incidences of aggressive behaviors (total daily instances of aggression/N) are graphed in blocks of two days in Figure 2.

An analysis of variance was performed on the number of aggressions initiated by the experimental subjects against each of the target males. Also, the incidences of aggression initiated by each of the target animals against each of the midrange subjects were included in the analyses. A significant value was obtained $[F(3 / 44)$ $=60.45, \mathrm{p}<.01]$. A posteriori comparisons examined mean performance differences by the Scheffé method (.05 confidence level). The results revealed that, indeed, the dominant target animals exhibited more aggressions against the midrange subjects than did the submissive target animals. Moreover, the midrange rats were more aggressive in the presence of the submissive animals than they were in the presence of the dominant animals. To summarize, the midrange subjects chose to affiliate with the submissive animal, where they were being aggressed against the least and were aggressing the greatest amount.

\section{EXPERIMENT II}

The findings of the first experiment demonstrate that an animal does not indiscriminately respond to all sources of social contact. A moderately aggressive rat prefers to affiliate with a less aggressive rather than a more aggressive conspecific. Yet, the paradigm of Experiment I forced the experimental rat to affiliate with another rat on every trial. A second experiment was proposed to investigate an animal choosing between another animal and an empty goal area.

The "social vs. empty goalbox" paradigm offers a large number of possible combinations of animals to investigate gregariousness and aggression. The strategy chosen, however, was limited to one. The second experiment was designed to vary the amount (high, medium, or low levels) of aggression received by the experimental subject when in the presence of another animal and the subsequent probability of affiliation. This strategy necessitated varying the aggressiveness of both the experimental subject and the target animal.

Three groups of the experimental subjects were used. Dominant rats were allowed to choose an empty goalbox or a submissive target animal with whom it would receive few return aggressions. Midrange aggressive anımals were given a comparable choice, though the presumption from earlier data (Logan, 1971) was that the submissive targets would exhibit more aggressiveness against midrange animals than against dominant animals. Finally, submissive animals were allowed a choice between an empty area and a highly aggressive, dominant target rat.

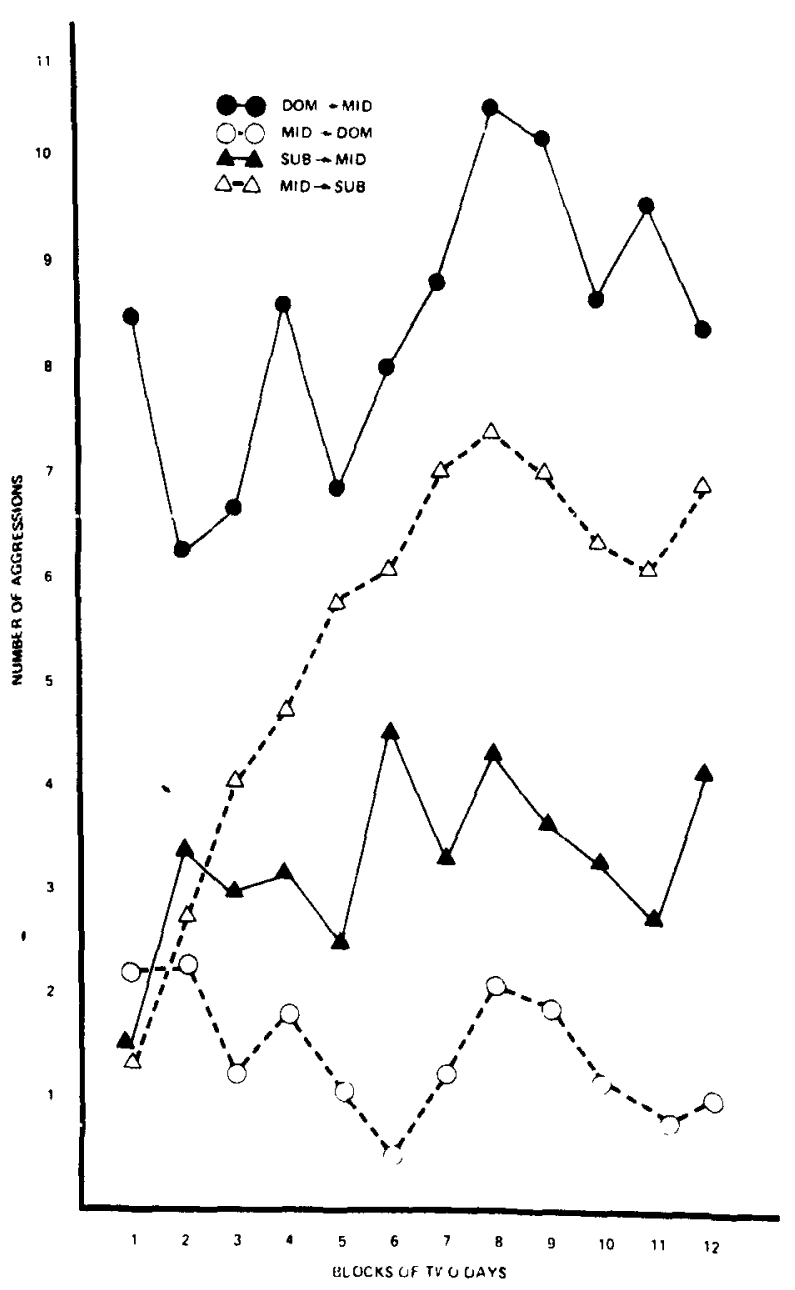

Figure 2. The individual mean number of aggressions by the midrange experimental animals and by the dominant and submissive target animals.

\section{Method}

Subjects. Sixty male albino rats obtained from a commercial supplier were used. The experimentally naive animals were 90-120 days of age at the beginning of the experiment and were individually housed. The animals were placed on water deprivation (see Experiment 1) for aggressiveness testing. Otherwise, the animals were allowed ad-lib food and water.

Apparatus. The same T-maze and water dominance box used in the first experiment were used in the present investigâtioñ.

Procedure. The males were initially water-deprived and observed in the water-dominance box to establish the relative aggressiveness of each animal. The 16 most aggressive, the 20 least aggressive, and the 12 midrange aggressive animals were retained. The other animals were discarded from the experiment.

The general procedure was identical to that of the first experiment. However, rather than a choice between two animals, the experimental subjects had a choice between a target animal and an empty goal area. Twelve of the 16 dominant animals, the 12 midrange animals, and 12 of the 20 submissive rats were randomly selected to be the experimental subjects in Groups 1 . 2 , and 3 , respectively. The remaining four dominant rats served as targets for Group 3. Four of the remaining submissive rats served as targets for Group 1, and four other submissive animals were targets for Group 2. 


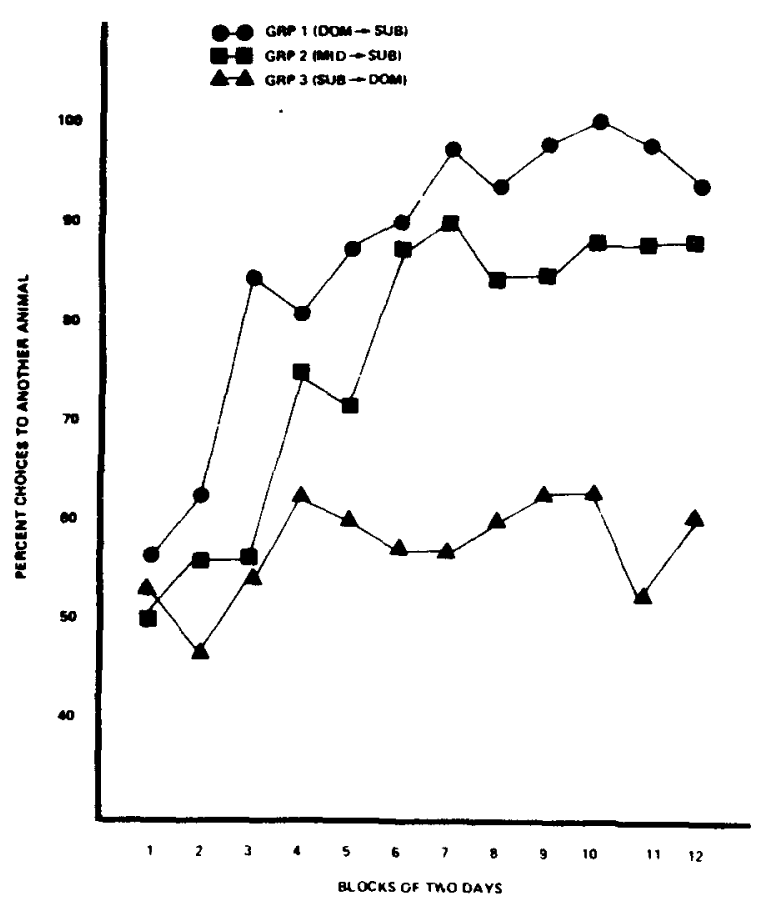

Figure 3. The percentage of choices by the experimental animals to the target rat and away from the empty compartment.

Thus, the highly aggressive, dominant subjects (Group 1) were given a choice between an empty goal area and a less aggressive, submissive target animal. The midrange aggressive subjects (Group 2) were allowed a choice between a submissive target and an empty area. The submissive subjects (Group 3) were allowed to choose between a dominant target and an empty goal. The target animal was in the black arm of the maze for half the experimental animals in each group and in the white side for the other rats.

Each of the subjects was given four daily spaced trials, two free and two forced. The animals were run for 24 days and 96 trials, 48 trials to the target animal and 48 trials to the empty goal area.

\section{Results}

The findings of the second experiment confirm and extend the results of Experiment 1 . The experimental question of interest pertains to gregariousness as influ. enced by the varying levels of aggressiveness initiated by the target animal. Groups 1 and 2 differ from each other on one dimension (subject dominance), but Group 3 differs from the other two groups on two dimensions (subject and target dominance). As a result, between-group comparisons are a bit more difficult.

Nonetheless, comparisons within groups suggested a relationship between affiliation and aggression in rats. An animal's gregariousness is importantly influenced by the level of aggressiveness when the animal is in the presence of the conspecific. An examination of choice behaviors and incidences of aggression suggests that there is an inverse relationship between an animal's preferences for affiliation and the intensity of being aggressed against.
Preference behaviors. The number of choices on the two daily free-choice trials to the target animal was recorded for each animal. Those data were combined within each of the three groups and appear in Figure 3 as the mean percentage of choices to the other animal. The results suggest that the dominant experimental animals (Group 1) developed a rapid and very strong preference for the submissive target animal over the empty goal area.

The midrange aggressive anımals (Group 2) appear to similarly exhibit a high preference for affiliation with a submissive target rat rather than the empty area. Yet, the level of preference is somewhat reduced relative to Group 1. In contrast were the preference data of the submissive experimental subjects of Group 3. Those animals appear to minimally prefer the dominant target rat, but frequently chose the empty goalbox instead.

Three $t$ tests were performed on the number of choices to the larget rat by each of the three groups to examine the hypothesis that $\mu=50 \%$. The hypothesis was rejected for Groups 1, 2, and $3[\mathrm{t}(11)=58.96$, $\mathrm{p}<.01 ; \mathrm{t}(11)=29.46, \mathrm{p}<.01, \mathrm{t}(11)=2.26$, $\mathrm{p}<.05$, respectively]. Thus, all three groups of experimental animals significantly preferred to affiliate with the target animal rather than enter an empty compartment.

An analysis of variance was performed to determine whether the three groups differed in number of choices to their respective target anmals. The iesults revealed a significant value $[F(3 / 32)=21.49, p<.01]$. Subse . quent a posterior comparisons of mean performance differences using the Schefté method (.05 confidence interval) demonsirated that the three groups differed significantly from each other. Therefore. though all the animals preferred affiliation, the three groups of rats chose the other arumal at different frequencies.

Aggressive behaviors. With the free-forced trials, the experimental subjects in each group were exposed to a target animal twice each day. The number of aggressions both by and against the subject was tallied. Those aggression scores were combined for each group and appear as means in blocks of 2 days in Figure 4.

The aggression data of Group 1 were predictable. The dominant experimental rat was considerably more aggressive than the submissive target animal $[t(11)=$ 4.93. $p<.01]$ Moreover, the submissive target animal very intrequently aggressed against the dominant animal.

The aggression data of Group 2 essentially confirmed the earlier fincings by Logan (1971). The midrange experimental subjects were more aggressive than the submissive targets $[t(11)=2.46, p<.05]$. However, the targets exhibited some amount of aggression over the training days. The Group 3 animals also differed in incidences of aggression $[\mathrm{t}(11)=6.61, \mathrm{p}<.01]$, though the dommant target anmals were the primary aggressors.

Inspection of Figure 4 suggests that the major difference between the aggression scores of Group 1 and Group 2 were the aggressive behaviors of the target rat. 
A post hoc $t$ test was performed to compare the aggression scores of the experimental groups of Groups 1 and 2 . The groups did not significantly differ $[t(11)=1.07]$. However, a second $t$ test compared the aggressions of the submissive target animals of the two groups and revealed a significant value $[\mathrm{t}(11)=2.32, \mathrm{p}<.05]$. That is, the midrange subjects of Group 2 chose the target animal less often than the dominant subjects of Group 1. Moreover, the midrange animals were being aggressed against at higher levels than the dominant subjects were being aggressed against by their respective submissive target animals.

\section{DISCUSSION}

Rats may congregate for reasons other than social contact; for example, the presence of food. Nonetheless, the data suggest that they may seek affiliation for social interaction as well. Moreover, the two experiments demonstrate that rats will learn a discrimination in order to obtain an opportunity for social interaction. Yet, it seems that animals are rather selective in their affiliative responses. Rats are not attracted to nonsocial stimuli, such as a tennis ball, and are only slightly attracted to anesthetized, stuffed, or caged rats. But they are highly attracted to free moving rats (Latané, Joy, Meltzer, Lubell, \& Cappell, 1972).

The present data extend that conclusion to include the relative aggressiveness of the other animal as an important determinant of gregariousness. Animals will select an alternative which allows for social interaction with a same-sex conspecific. The appeal of affiliation may, however, be reduced by the aversive stimulation of being the object of the other animal's aggressiveness. As the aggressiveness of the target animal was decreased from high to medium to low levels (Groups 3, 2, and 1, respectively, of Experiment II), there was a corresponding increase in the experimental subjects' gregariousness.

These data bear striking resemblance to findings from the individual animal learning literature. Logan (1969) ran hungry rats individually in a choice situation. A larger amount of food and an electric footshock were located at one alternative and a smaller amount of food but no shock was located at the other alternative. The animals chose the food-shock alternative progressively less with increases in the intensity of the shock. With a sufficiently aversive shock, the animals actually developed a preference for the less food/no shock alternative.

A closer examination of the data suggests two additional conclusions. The midrange animals of Experiment I decidedly preferred the submissive targets, who were considerably less aggressive than the dominant targets. At the same time, however, the midrange subjects aggressed more against the submissive targets than against the dominant targets. These data suggest that the affilative response may be influenced, not
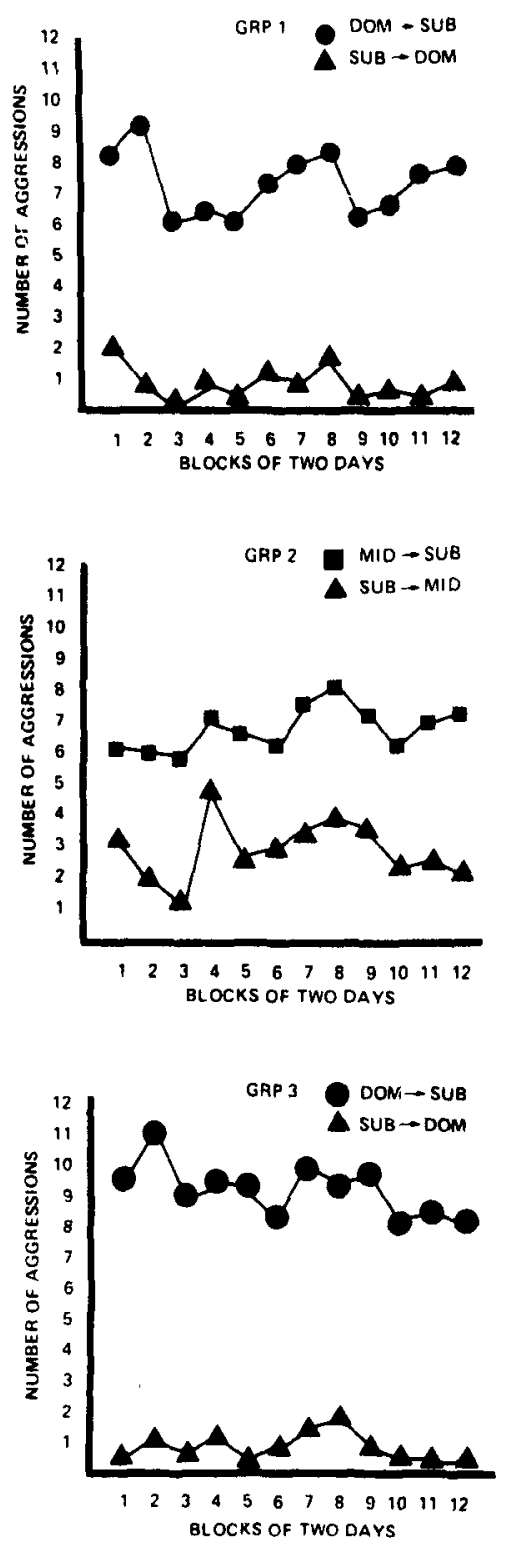

Figure 4. The individual mean number of aggressions by the experimental subjects and by their respective target animals.

only by the aggressiveness of the target animal, but by the opportunity to engage in aggressive behaviors themselves.

On the other hand, the results of Experiment II appear to oppose that notion. The dominant experimental subjects of Group 1 were more gregarious than the midrange experimental rats of Group 2. Yet, the primary differences in aggressive behaviors between Groups 1 and 2 were those by the target animals. Though the experimental subjects of the two groups exhibited comparable levels of aggression, the submissive targets of Group 2 were notably more aggressive toward the midrange subjects than were the submissive targets 
of Group 1 against the dominant subjects. These data point toward the aversiveness of the submissive target as the distinguishing factor producing the varying levels of affiliation.

A second observation of interest was that the submissive subjects of Group 3 preferred to affiliate with a highly aggressive target animal, though at a much reduced level relative to the other subjects. The submissive subjects' choice behaviors were somewhat surprising, particularly considering the data with individual animals (Logan, 1969). A sufficiently aversive footshock reversed the individual animal's preference behavior. The results in the present, social setting indicate that either (1) being the object of a dominant target rat's aggressiveness was not particularly aversive, or (2) the opportunity for social interaction was a powertul incentive capable of attenuating the effects of a noxious stimulus. The latter explanation appears a bit more tenable. The submissive subjects appeared to experience some amount of pain in interaction with the dominant target. as evidenced by squealing, freezing, and other emotional behaviors.

To be sure, a particularly violent attack on a trial by the dominant target animal had an immediate effect. On subsequent trials, the submissive subjects would tend to freeze in the runway of the alley and the probability of choosing the target anımal appeared to drop, for a short time. There was a return to the previous moderate level of affiliation with only a few more trials.

In summary, the results of the experiment suggest several conclusions. Male rats will actively seek a samesex conspecific. The social interaction may evolve into an aggressive bout (Cairns \& Scholz, 1973) with some number of return aggressions. As a result, the attractiveness of the other animal is reduced dependent upon the intensity of being the object of an aggressive attack Moreover, these findings suggest that the two-choice paradigm is a procedure which can be fruitfully used to more fully understand the intimate relationship between aggression and affiliation.

\section{REFERENCES}

Angermeier, W. F. Some basic aspects of socıal reinforcements in albino rats. Journal of Comparative and Physiological Psychology, 1960, 53, 364-367.

Barnett, S. A. The rat A study in behavior Chicago: Aldine Press, 1963.

Cairns, R. B., \& Scholz, S. D. Fighting in mice: Dyadic escalation and what is learned. Journal of Comparative and Physiological Psychology, 1973, 85, 540-550.

Ewer, R. F. Etfiology of mammals. New York Plenum Press, 1968 .

Grant. E. C. An analysis of the social behavior of the male laboratory rat. Behaviour, 1963, 21, 260-281.

Grant, E. C., \& Mackintosh, J. H. A comparison of the social postures of some common laboratory rodents. Behaviour. $1963.21,246-259$.

Lagerspetz, L. Studies on the aggressive behavior of mice. Helsink1: Suomalainen Tiedeak atemia, 1964.

Latané, B.. \& Hothersall, D. Social attraction in mammals. In P. C. Dodwell (Ed.), New horizons ir psuchologv 11 Great Britan: Penguin Books, 1972.

Latané, B., Joy, V., Meltzer, J., Lubell, B., \& Cappell, H. Stımulus determinants of social attraction in rats. Journal of Comparative and Physiological Psychology, 1972, 79, 13-21.

Logan, F. A. The negative incentive value of punshment. In B. A. Campbel \& R. M. Church (Eds.). Punishment and alersive behavor New York Appleton-Century-Crofts, 1969.

Logan, F. A. Domirance and aggression. In H D. Kimmel (Ed.). Experimental psychopathology. New York. Academic Press. 1971.

Rowell, T. The concept of social dominance. Eehavioral Biology, $1974,11,131.154$.

Scott, J. P. Agonistic behavior of mice and rats: A review. American Zoologist, 1966, 6, 683-701.

Sloan, L, R., \& Latane, B. Social deprivation and stimulus satiation in the albino rat. Journal of Comparative and Physiological Psychology, 1974, 87, 1148-1156.

Syme, G. J., Pollard, J. S., Syme, L. A., \& Reid, R. M. An analysis of the limited access measure of social dominance in rats. Animal Behaviour, 1974, 22, 486-500.

Taylor, G. T. Stimulus change and complexity in exploratory behavior. Animal Learning \& Behavior, 1974, 2, 115-118.

Taylor, G. T. Male aggression in the presence of an estrous female. Journal of Comparative and Physiological Psychology, 1975, 89, 246-252.

Taylor, G. T., \& Moore, S. Social position and competition in laboratory rats. Journal of Comparative and Physiological Psychology, 1975, 88, 424-430.

Zook, J. M., \& Adams, D. B. Competitive fighting in the rat. Journal of Comparative and Physiological Psychology, 1975 , $88,418-423$.

\section{NOTE}

1. The nonparametric chi square was used where the "independence" assumption could not be met, and the more powerful $t$ test was used at all other times.

(Received for publication April 2, 1975 ; revision accepted September 29. 1975.) 